\title{
EDITORIAL \\ Our new feature: Narrative Medicine
}

Pediatric Research (2020) 88:343-344; https://doi.org/10.1038/s41390020-0983-6

In the past two decades the new field of "Narrative Medicine" has emerged from the meeting of medicine and the humanities. Narrative Medicine is the practice of listening for stories in healthcare. Rita Charon, the field's leading pioneer, explains that Narrative Medicine responds to the need in healthcare for doctors (as well as nurses, social workers, physician assistants, and other health care providers) to provide better care for patients, and to facilitate new thinking about health and medicine. Charon states, "patients lament that their doctors don't listen to them or that they seem indifferent to their suffering." ${ }^{11}$ Such neglect of empathy, compassion, and forgetting of the internal life of the patient itself suggests a need for healing and education through narration because "to be of clinical help requires that doctors enter the worlds of their patients, if only imaginatively, and to see and interpret these worlds from the patients' point of view." ${ }^{2}$ In response to this burgeoning interdisciplinary field, Pediatric Research is thus proud to announce a new category of article for publication in the field of Narrative Medicine. We would like to provide a forum for stories from physicians of their own personal experiences that inspire us. Many of us are driven by the need to advance care for our patients and we are emotionally attached to their outcomes. Physicians and other health care works are usually not allowed to mourn in public. Yet, now with the crisis of Covid19 taking center stage in our daily reports on the challenges confronting health care, we hope that this forum will allow for not only "Covid stories" to be shared, but also the many other important narratives that emerge from our experiences as health care providers and patients. As we move forward out of this crisis and into routine care, we should not go back to business as usual. We should learn from this moment as we will benefit as practitioners by listening to the stories of our patients and one another's stories. Our goal is to inform and inspire readers, to offer authors a place to share their sorrows and joys, and ultimately, through such creative expression of the healer's bent, to foster the best care we can for our patients.

Storytelling is ancient and has powerful effects on human motivation. Storytelling helps us view the comedy and tragedy of life with new eyes. We feel less distressed both by telling stories and reading them. We feel less alone when we can empathize with the journeys taken and told by fellow travelers. Narrative Medicine aims to combine the power of literature and uses of all the humanities and arts combined with evidence-based medicine to improve human health and our harmony with both nature and culture. ${ }^{3,4}$

In medicine we use case histories to illustrate clinical learning points. We also use biographical narratives to offer guidance, inspiration, and moral direction. It is our experience as humans in a complex world that fills the vacuum where no hard evidence is available. Some things cannot be empirically proven and yet we feel them to be true to our nature and our experience. These are the things we find in stories and these are the things that give us strength in times of trouble. Understanding and appreciating narratives in clinical medicine can help the clinician to combine experiential knowledge, evidence-based medicine, and psychosocial perspectives. Even current neuroscience has discovered that the human mind processes stories more effectively than logic. We who work in the medical fields should thus embrace these powerful tools to assist our work with patients and our increasingly important task of caring for ourselves and each other as health care providers.

The healing powers of Narrative Medicine are being increasingly recognized, so much so that Universities have master degree programs in this subject. Examples of such programs include Columbia University and the University of Southern California. Students are drawn not only from medicine, but also from a variety of healthcare workers and those in the humanities for a multidisciplinary experience. It is time for all medical fields to listen and to learn from the trends of our times. Here in the era of COVID-19, we feel that it is especially important to launch this new initiative now. In this issue of Pediatric Research, we publish our two first Narrative Medicine pieces. ${ }^{5,6}$ Please read them and be moved.

\section{ACKNOWLEDGEMENTS}

This work was supported by International Pediatric Research Foundation.

\section{AUTHOR CONTRIBUTIONS}

V.J.C.: Substantial contributions to conception and design, revising the article critically for important intellectual content; final approval of the version to be published. E.J.M.: Substantial contributions to conception and design, revising the article critically for important intellectual content; final approval of the version to be published. C.F.B. Substantial contributions to conception and design, revising the article critically for important intellectual content; final approval of the version to be published.

\section{ADDITIONAL INFORMATION}

Competing interests: The authors declare no competing interests.

Publisher's note Springer Nature remains neutral with regard to jurisdictional claims in published maps and institutional affiliations.

Vera J. Camden ${ }^{1}$, Eleanor J. Molloy ${ }^{2}$ and Cynthia F. Bearer (D) $^{3}$ ${ }^{1}$ Department of English, Kent State University, Kent, OH, USA;

${ }^{2}$ Paediatrics and Child Health, Trinity College, Trinity Academic Centre, Tallaght Hospital, The University of Dublin, Dublin, Ireland and ${ }^{3}$ Department of Pediatrics, UH Rainbow Babies and Children's Hospital, Case Western Reserve University School of Medicine, Cleveland, $\mathrm{OH}, \mathrm{USA}$ Correspondence: Cynthia F. Bearer (Cynthia.bearer@UHhospitals.org)

\section{REFERENCES}

1. Charon, R. Narrative Medicine: Honoring the Stories of Illness, 3 (Oxford Press, New York, 2008).

2. Charon, R. Narrative Medicine: Honoring the Stories of Illness, 9 (Oxford Press, New York, 2008). 
3. Holmgren, L., Fuks, A., Boudreau, D., Sparks, T. \& Kreiswirth, M. Terminology and praxis: clarifying the scope of narrative in medicine. Lit. Med. 29, 246-273 (2011).

4. Chin-Yee, B., Messinger, A. \& Young, L. T. Three visions of doctoring: a Gadamerian dialogue. Adv. Health Sci. Educ. Theory Pract. 24, 403-412 (2019).
5. Falck, A., Hussey-Gardner, B., Purdy, P., \& Pray, N. Honoring Gus: lessons learned about creating memories in the NICU. Pediatr. Res. (2019). https://doi.org/10.1038/ s41390-019-0638-7.

6. Ibrahim, J. When a neonatologist become the father of a NICU baby: How do I feel and how did I change? Pediatr. Res. (2019). https://doi.org/10.1038/s41390-019-0652-9. 